\title{
Synergistic and antagonistic effects of immunomodulatory drugs on the action of antifungals against Candida glabrata and Saccharomyces cerevisiae
}

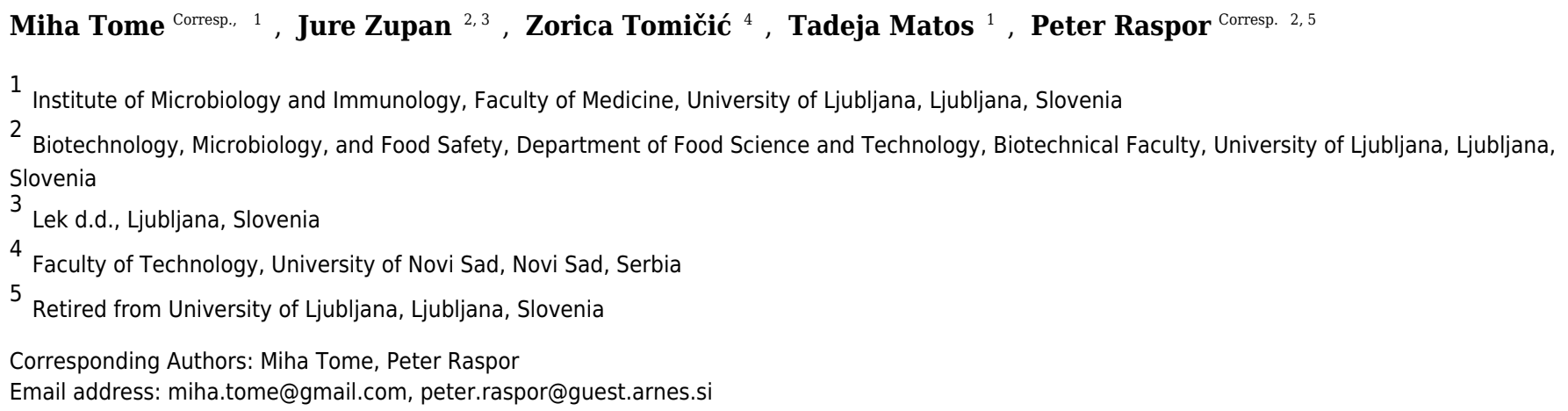

Candidemia and other forms of invasive fungal infections caused by Candida glabrata and to a lesser extent Saccharomyces cerevisiae are a serious health problem, especially if their steadily rising resistance to the limited range of antifungal drugs is taken into consideration. Various drug combinations are an attractive solution to the resistance problem, and some drug combinations are already common in the clinical environment due to the nature of diseases or therapies. We tested a few of the common antifungalimmunomodulatory drug combinations and evaluated their effect on selected strains of $C$. glabrata and S. cerevisiae. The combinations were performed using the checkerboard microdilution assay and interpreted using the Loewe additivity model and a model based on the Bliss independence criterion. A synergistic interaction was confirmed between calcineurin inhibitors (Fk506 and cyclosporine A) and antifungals (fluconazole, itraconazole, and amphotericin B). A new antagonistic interaction between mycophenolic acid (MPA) and azole antifungals was discovered in non-resistant strains. A possible mechanism that explains this is induction of the Cdr1 efflux pump by MPA in C. glabrata ATCC 2001. The Pdr1 regulatory cascade plays a role in overall resistance to fluconazole, but it is not essential for the antagonistic interaction. This was confirmed by the Cgpdr1 $\Delta$ mutant still displaying the antagonistic interaction between the drugs, although at lower concentrations of fluconazole. This antagonism calls into question the use of simultaneous therapy with MPA and azoles in the clinical environment. 
1 Synergistic and antagonistic effects of immunomodulatory drugs on the action of

2 antifungals against Candida glabrata and Saccharomyces cerevisiae

3

4 Miha Tome ${ }^{1}$, Jure Zupan ${ }^{2,3}$, Zorica Tomičić ${ }^{4}$, Tadeja Matos ${ }^{1}$, Peter Raspor ${ }^{2,5}$

5

$6{ }^{1}$ Institute of Microbiology and Immunology, Faculty of Medicine, University of Ljubljana,

7 Zaloška 4, 1000 Ljubljana, Slovenia;

$8{ }^{2}$ Biotechnology, Microbiology, and Food Safety, Department of Food Science and Technology,

9 Biotechnical Faculty, University of Ljubljana, Jamnikarjeva 101, 1000 Ljubljana, Slovenia;

$10{ }^{3}$ Lek d.d., Verovškova ulica 57, 1000 Ljubljana, Slovenia (address at time of writing);

$11{ }^{4}$ Faculty of Technology, University of Novi Sad, Bulevar cara Lazara 1, 21101 Novi Sad,

12 Serbia;

$13{ }^{5}$ Retired from University of Ljubljana, Kongresni trg 12, 1000 Ljubljana, Slovenia.

15 Corresponding authors:

16 Miha Tome, miha.tome@gmail.com or miha.tome@mf.uni-lj.si (+386 40895 218)

17 Peter Raspor, peter.raspor@guest.arnes.si (+386 41335 113) 


\section{Abstract}

20 Candidemia and other forms of invasive fungal infections caused by Candida glabrata and to a

21 lesser extent Saccharomyces cerevisiae are a serious health problem, especially if their steadily

22 rising resistance to the limited range of antifungal drugs is taken into consideration. Various drug

23 combinations are an attractive solution to the resistance problem, and some drug combinations are

24 already common in the clinical environment due to the nature of diseases or therapies. We tested 25 a few of the common antifungal-immunomodulatory drug combinations and evaluated their effect

26 on selected strains of $C$. glabrata and $S$. cerevisiae. The combinations were performed using the 27 checkerboard microdilution assay and interpreted using the Loewe additivity model and a model 28 based on the Bliss independence criterion. A synergistic interaction was confirmed between 29 calcineurin inhibitors (Fk506 and cyclosporine A) and antifungals (fluconazole, itraconazole, and amphotericin B). A new antagonistic interaction between mycophenolic acid (MPA) and azole antifungals was discovered in non-resistant strains. A possible mechanism that explains this is induction of the Cdr1 efflux pump by MPA in C. glabrata ATCC 2001. The Pdr1 regulatory cascade plays a role in overall resistance to fluconazole, but it is not essential for the antagonistic interaction. This was confirmed by the $\operatorname{Cg} p d r 1 \Delta$ mutant still displaying the antagonistic interaction between the drugs, although at lower concentrations of fluconazole. This antagonism calls into question the use of simultaneous therapy with MPA and azoles in the clinical environment.

\section{Introduction}

The frequency and associated mortality of candidemia and other forms of invasive candidiasis have not decreased over the past two decades despite the introduction of several

41 extended-spectrum triazole and echinocandin antifungal drugs for use in prophylaxis, empiric 
42 therapy, and targeted therapy (Pfaller \& Diekema, 2007; Pfaller \& Castanheira, 2016). Candida

43 albicans is the dominant pathogen, but the incidence of invasive infections caused by Candida

44 glabrata has been steadily rising (Pfaller et al., 2012b, 2014). The most vulnerable populations

45 include transplant patients, patients with AIDS or cancer, those on immunosuppressive therapy,

46 patients receiving total parenteral nutrition, and premature infants (Pfaller \& Diekema, 2010;

47 Whaley \& Rogers, 2016). In certain populations, C. glabrata even surpasses C. albicans as the

48 leading pathogen; these include patients with hematologic malignancies, diabetes mellitus, and

49 patients with an abdominal source of infection (Hachem et al., 2008; Segireddy et al., 2011; Khatib

50 et al., 2016; Whaley \& Rogers, 2016). The reasons for the rise of C. glabrata infections include

51 the introduction of fluconazole in 1990 and its widespread prophylactic use against fungal

52 infections (Berrouane, Herwaldt \& Pfaller, 1999), a higher rate of antifungal use and intrinsic or

53 acquired resistance of C. glabrata to both fluconazole and echinocandins (Silva et al., 2012; Pfaller

54 et al., 2012a; Alexander et al., 2013; Pfaller \& Castanheira, 2016; Colombo, Júnior \& Guinea,

55 2017), and better identification of non-albicans species in the clinic (Liguori et al., 2009).

One of the main problems when dealing with C. glabrata is its intrinsically low

57 susceptibility to azole antifungals (Vermitsky \& Edlind, 2004) and its ability to develop resistance

to several antifungal drug classes (Pfaller, 2012; Glöckner \& Cornely, 2015). For example,

resistance to azole antifungals in clinical isolates is mostly connected to mutations in the gene

PDR1, which encodes the transcription factor for the pleiotropic drug response (Vermitsky \&

61 Edlind, 2004). Activating mutations in PDRI lead to distinct patterns of altered gene expression

62 among Pdr1 targets, commonly leading to overexpression of efflux pumps that lower the

63 bioavailability of the azoles, thus lowering their effectiveness (Whaley \& Rogers, 2016). The

64 efflux pumps most commonly associated with azole resistance in C. glabrata are the ATP-binding 
65

66

67

68

69

70

71

72

73

74

75

76

77

78

cassette (ABC) transporters Cdr1 (Sanglard, Ischer \& Bille, 2001), Cdr2/Pdh1 (Miyazaki et al., 1998), and Snq2 (Torelli et al., 2008). Alternative azole resistance mechanisms include petite mutants with increased expression of $C D R 1$ and $C D R 2$ through Pdr1 induction and lower levels of ergosterol intermediates (Brun et al., 2004; Tsai et al., 2006; Whaley \& Rogers, 2016). Namely, azoles inhibit Erg11 (lanosterol 14- $\alpha$ demethylase in ergosterol biosynthesis), causing disruption of the membrane and the accumulation of toxic sterol intermediate (Cowen, 2008). Documented mechanisms of azole resistance also include Upc2A regulated uptake of exogenic sterols with the Aus 1 transporter (Nakayama et al., 2007; Nagi et al., 2011), and mutations or changes in the expression of target gene ERG11 and genes involved in sterol intermediate synthesis (ERG3, ERG24) (Morio et al., 2012; Whaley et al., 2017). However, C. glabrata clinical isolates do not appear to utilize azole resistance mechanisms that involve mutations or changes in the expression of genes in the ergosterol biosynthesis pathway (Sanguinetti et al., 2005).

S. cerevisiae has resistance mechanisms to azole antifungals similar to those in $C$. glabrata through the increased activity of efflux pumps (Pdr5 homologue of Cdr1) induced by Pdr1 (MoyeRowley, 2003), and the dysfunctional mitochondria of petite mutants (Kontoyiannis, 2000). $S$. cerevisiae is not usually associated with pathogenesis; however, instances of Candida-like infections (Aucott et al., 1990; Murphy \& Kavanagh, 1999; Piarroux et al., 1999; Wheeler et al., 2003), often connected with its probiotic variant Saccharomyces boulardii (nom. nud.), have been reported (Lherm et al., 2002; Cassone et al., 2003; Enache-Angoulvant \& Hennequin, 2005; Roy et al., 2017). Food-oriented $S$. cerevisiae and pathogenic C. glabrata therefore present an interesting link for observing the development of various aspects of adaptations to the human host and the mechanisms of evolution in the Saccharomycetaceae (Wheeler et al., 2003; Roetzer, Gabaldón \& Schüller, 2011; Bolotin-Fukuhara \& Fairhead, 2014). S. cerevisiae serves as a model 
88 organism, and so its regulatory networks and gene functions are extensively studied. A high degree

89 of homology with C. glabrata therefore makes it possible to utilize the accumulated knowledge

90 from the model organism and apply it to the pathogen.

91 Developing new antifungals agents is difficult and costly. Synergistic and additive drug

92 treatments are potential strategies for controlling resistance development and evolution because

93 the administration of multiple drugs may disrupt several mechanisms or processes in the pathogen

94 and thus minimize the selection of resistant strains (Yeh et al., 2009; Bollenbach, 2015). The

95 combination of antifungals flucytosine (5FC) and amphotericin B (AMB) is recommended by the

96 Infectious Diseases Society of America for Candida infections (Pappas et al., 2015) due to the

97 high rate of resistance developed during 5FC monotherapy (Barchiesi et al., 2000). Other

98 combinations between two antifungals have been put through clinical trials (Scheven et al., 1992;

99 Ghannoum \& Elewski, 1999; Rex et al., 2003; Pachl et al., 2006), but so far only the 5FC+AMB

100 combination therapy has a clinical role (Pappas et al., 2015). Common combinations studied are

101 between a commercial antifungal and a specific inhibitor of a protein of interest; for example,

102 antifungals combined with Hsp90 inhibitors (Cowen, 2013; Veri \& Cowen, 2014) or protein kinase

103 C inhibitors (LaFayette et al., 2010). Several promising drug combinations against pathogenic

104 fungi have recently been reviewed (LaFayette et al., 2010; Liu et al., 2014; Cui et al., 2015; Svetaz

105 et al., 2016).

106 Due to the nature of the therapy already employed in the clinical environment, drug

107 combinations are often overlooked with regard to their effect on the pathogens, and treatments can

108 become problematic because of unexpected interactions (Henry et al., 1999). Possible side effects

109 and the toxicity of certain drug-drug interactions usually focus on the host, whereas the actual

110 pathogens and their role in these interactions are rarely taken into consideration (Nett \& Andes, 
111 2016). Simultaneous therapy with several overlapping drugs often occurs in the clinic. Such

112 instances often involve administration of antifungal and immunomodulatory drugs (Pfaller \&

113 Castanheira, 2016). Many immunomodulatory drugs have conserved targets in fungal pathogens;

114 for example, calcineurin is crucial for the survival during membrane stress (Cruz et al., 2002), and

115 calcineurin inhibitors (cyclosporine A (CsA) and Fk506) have antifungal properties (Steinbach et

116 al., 2007; Li et al., 2015; Denardi et al., 2015; Yu, Chang \& Chen, 2015). Methotrexate (MTX),

117 which blocks folic acid metabolism, also has antifungal properties, as it inhibits ergosterol

118 production in C. albicans and makes it more susceptible to azoles (Navarro-Martínez, Cabezas-

119 Herrera \& Rodríguez-López, 2006). Mycophenolic acid (MPA) targets inosine-5'-monophosphate

120 dehydrogenase, which is a crucial enzyme for the de novo synthesis of guanine nucleotides (Shah

121 \& Kharkar, 2015). MPA has antifungal properties and is synergistic with AMB in C. albicans

122 (Banerjee, Burkard \& Panepinto, 2014).

123 The study's main goal was to observe whether drug combinations of immunomodulatory

124 and antifungal drugs have any modulatory effects on the selected C. glabrata and S. cerevisiae

125 isolates. Synergy between calcineurin inhibitors and antifungals was detected. Antagonism

126 between MPA and fluconazole (FLC) in most non-resistant strains was detected as well. This

127 antagonism was unexpected, and therefore the underlying mechanism was briefly investigated.

128 Because FLC resistance is commonly connected to the activation of Pdr1 and subsequent

129 overexpression of the Cdr1 efflux pump, their gene expression was analysed. MPA appears to

130 induce overexpression of the CDR1 efflux pump, but the central role of Pdr1 is questionable. This

131 was further confirmed in a Cgpdr1 $1 \Delta$ mutant, in which an antagonistic interaction between FLC

132 and MPA was observed, although at lower concentrations of FLC. This antagonistic interaction 
133 between FLC and MPA opens the potential to further explore the underlying mechanism and its

134 impact in the clinical environment.

135

136 Materials \& Methods

137 Strains. Five Saccharomyces cerevisiae, six Candida glabrata clinical isolates and one $S$.

138 cerevisiae non-clinical isolate were selected from the Collection of Industrial Microorganisms

139 (ZIM) at the Biotechnical Faculty, Slovenia (Table 1). These were selected from 96 clinical isolates

140 (40 S. cerevisiae and 56 C. glabrata; full list of strains is in Supplemental Files

141 "List_of_strains.xlsx") and nine non-clinical S. cerevisiae isolates based on their minimal

142 inhibitory concentrations (MICs) obtained by the reference method for broth dilution antifungal

143 susceptibility testing of yeasts (CLSI M27-A3) (CLSI, 2008). The criterion was to select strains

144 with different MICs to cover several spectra of antifungal resistance. S. cerevisiae strain Sc6 from

145 sorghum beer was selected because it displayed high tolerance $(16 \mathrm{mg} / \mathrm{l})$ towards fluconazole for

146 a non-clinical isolate. Candida parapsilosis ATCC 22019 and Candida krusei ATCC 6258 were

147 used as the control strains in the drug susceptibility and checkerboard assays. In addition, to

148 explore the antagonistic mechanism of MPA and azole antifungals, we used C. glabrata ATCC

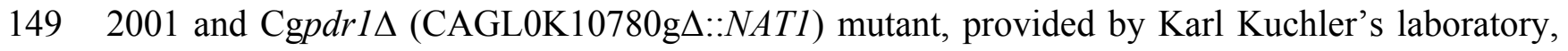

150 Medical University of Vienna, from their deletion library (Schwarzmüller et al., 2014). Cgpdr1 $\Delta$

151 is isogenic to C. glabrata ATCC 2001.

152

153 Table 1

154 

20) at $-80{ }^{\circ} \mathrm{C}$. They were revitalized and routinely grown on yeast peptone dextrose (YPD) agar

157 plates (2\% Bacto Peptone, $1 \%$ yeast extract, $2 \%$ dextrose, and $2 \%$ Bacto agar) at $35{ }^{\circ} \mathrm{C}$, regularly 158 sub-cultured before each experiment. Throughout the assays we also used YPD broth (2\% Bacto 159 Peptone, $1 \%$ yeast extract, $2 \%$ dextrose), Sabouraud dextrose agar (3\% Sabouraud dextrose from 160 Sigma-Aldrich, 2\% Bacto agar), and RPMI (1.04\% RPMI-1640 from Sigma-Aldrich, 3.453\% 161 morpholinepropanesulfonic acid from Sigma-Aldrich, $\mathrm{pH}$ adjusted to $\mathrm{pH} 7$ with $10 \mathrm{M} \mathrm{NaOH}$ 162 solution) (Adams et al., 1998).

163 Drugs. Immunomodulatory drugs used for the screening were methotrexate (MTX), 164 mycophenolic acid (MPA) and its derivate mycophenolate mofetil, cyclosporine A (CsA), and 165 tacrolimus (Fk506). We also included a $\beta$-lactam antibiotic amoxicillin trihydrate (AMX) because 166 it is often administered simultaneously with immunomodulatory agents. Antifungal drugs used for 167 the initial screenings were amphotericin B (AMB), itraconazole (ITC), and fluconazole (FLC). For 168 further exploration of the antagonistic mechanism between MPA and azoles, we used 169 posaconazole (POS), ketoconazole (KCT), and voriconazole (VRC). All of the drugs were 170 obtained from Sigma-Aldrich, except Fk506, which was provided by Acies Bio.

171 Stock solutions of MPA, MTX, CsA, Fk506, AMB, ITC, POS, KCT, VRC, and CLO were 172 prepared in dimethyl sulfoxide (DMSO; Sigma-Aldrich), whereas AMX and FLC were diluted 173 directly in the medium of choice for the assay. All the final drug concentrations were made in 174 media (RPMI for drug susceptibility and checkerboard assay, YPD for further evaluation of the 175 antagonistic interaction). List of stock solutions is in Supplemental Files 176 “Optical_density_values.xlsx”. 
178 and to observe the effects of the drug combinations on them, we used CLSI M27-A3 checkerboard

179 microdilution assay (CLSI, 2008). Briefly, drug dilutions and combinations were prepared in

180 RPMI medium in microtiter plates. Negative (only medium) and positive (strain and medium

181 without drug) controls were included. Strains were grown on Sabouraud agar at $35^{\circ} \mathrm{C}$ and, after

$18224 \mathrm{~h}$, one colony was transferred in $1 \mathrm{ml} 0.85 \%$ saline solution. Inoculum was prepared by diluting

183 yeast cells in RPMI medium to $3-5 \times 10^{3}$ cells $/ \mathrm{ml}$ using the automatic Image J-counting technique

184 (Zupan et al., 2013). $100 \mu$ of this cell suspension was then transferred to $100 \mu$ of drug

185 suspension prepared in microplates. When the DMSO was used for drug dilution, it comprised <

$1861 \%$ of the final test volume in the microtiter well. Tested drug concentrations ranged from 200-2

$187 \mathrm{mg} / \mathrm{l}$ for MTX, 400-6.25 mg/1 for AMX, 120-2 mg/l for MPA, 400-0.25 mg/1 for Fk506, $18816-0.125 \mathrm{mg} / 1$ for CsA, 256-0.25 mg/1 for FLC, 256-0.25 mg/1 for ITC, 1-0.004 mg/1 for AMB, $18916-0.068 \mathrm{mg} / \mathrm{l}$ for $\mathrm{KCT}, 16-0.017 \mathrm{mg} / \mathrm{l}$ for $\mathrm{VRC}$, and $16^{-}-0.25 \mathrm{mg} / \mathrm{l}$ for POS. After incubation at $19037^{\circ} \mathrm{C}$ for 24,48 , or $72 \mathrm{~h}$, we measured the optical density at $600 \mathrm{~nm}\left(\mathrm{OD}_{600}\right)$ with a microplate 191 reader (Tecan). Background optical densities were subtracted from that of each well. In vitro 192 susceptibility and drug combination tests were performed at least in biological triplicates.

193 When we further investigated the observed mechanism of the antagonism between MPA 194 and additional azole antifungals versus C. glabrata ATCC 2001 and Cgpdr1 $\Delta$ mutant, we used a 195 version of the assay described above but replaced SAB and RPMI media with YPD agar plates 196 and broth, respectively. We have confirmed that the antagonistic effect in C. glabrata ATCC 2001 197 is present in both RPMI and YPD media, results are in Supplemental Files 198 “ATCC_2001_RPMI_YPD.xlsx". 
microdilution assays were analysed with the fractional inhibitory concentrations index (FICI)

201 based on the Loewe additivity model (Loewe, 1928), using the following equation: $\mathrm{FICI}=\mathrm{FIC}_{\mathrm{A}}+$

$202 \mathrm{FIC}_{\mathrm{B}}$, where $\mathrm{FIC}=\mathrm{MIC}_{\text {combination }} / \mathrm{MIC}_{\text {individual }}$. For azoles and immunomodulatory drugs $\mathrm{MIC50}$

203 was used, and MIC90 for AMB. FICI is interpreted as synergistic when $\leq 0.5$, indifferent when $>$

2040.5 and $<4$, and antagonistic when $\geq 4$ (Odds, 2003). For calculation of the FICIs when the MIC

205 resulted in an off-scale value, the next higher concentration (e.g., $>32=64 \mathrm{mg} / \mathrm{l}$ ) was used

206 (Moody, 2010). FICI $\mathrm{min}_{\text {in }}$ was reported as the FICI in all cases unless the FICI $_{\max }$ was greater than

207 4, in which case FICI $_{\max }$ was reported as the FICI for that particular data set (Meletiadis et al., 208 2005).

Bliss Independence. The expected effect of drug combinations was also calculated by a model based on the Bliss independence (BI) criterion, where we assume that the relative effect of

211 a drug at a particular concentration is independent of the presence of the other drug (Bliss, 1939;

212 Goldoni \& Johansson, 2007; Yeh et al., 2009). We calculated the predicted decrease of relative 213 growth ( $\left.\mathrm{E}_{\text {predicted }}\right)$ using the following equation: $\mathrm{E}_{\text {predicted }}=1-\mathrm{E}_{\mathrm{A}} * \mathrm{E}_{\mathrm{B}}$, where $\mathrm{E}_{\mathrm{A}}$ and $\mathrm{E}_{\mathrm{B}}$ are 214 individually measured relative growth inhibitions by drugs A or B, respectively. Positive or 215 negative deviations $\left(\Delta \mathrm{E}=\mathrm{E}_{\text {measured }}-\mathrm{E}_{\text {predicted }}\right)$ from this predicted decrease of relative growth 216 describe synergistic and antagonistic interactions, respectively (Yeh et al., 2009).

217 To interpret and summarize the entire interaction surface calculated by the BI criterion 218 among several different drug combination concentrations, we used previously described 219 interpretations (Meletiadis et al., 2005). Briefly, we summed all statistically significant $\Delta \mathrm{E}(\Sigma \mathrm{SSI})$, 220 determined the mean percentage (MSSI), and calculated the $95 \%$ confidence interval (CI). If it did 221 not include 0 and was positive or negative, statistically significant synergy or antagonism, 
222 respectively, was claimed for the entire data set. In addition, we also calculated the $\Sigma$ SSI and MSSI

223 for all the significant synergistic ( $\Sigma$ SYN and MSYN, respectively) and antagonistic ( $\Sigma$ ANT and

224 MANT, respectively) $\Delta \mathrm{E}$ separately. The absolute sum of all $\Sigma \mathrm{SYN}$ or $\Sigma \mathrm{ANT}$ was considered to

225 be a weak (0-100\%), moderate (100-200\%), or strong (> 200\%) interaction.

226 The interaction between two drugs was considered significant, if it was confirmed with at

227 least one model (either BI or FICI).

228 Gene expression. C. glabrata ATCC 2001 was grown in liquid YPD overnight at $37^{\circ} \mathrm{C}$.

229 In the morning, we diluted it in fresh YPD to $\mathrm{OD}_{600} 0.05$ and let it grow at $37{ }^{\circ} \mathrm{C}$ back to $\mathrm{OD}_{600}$

2300.1 (approximately $1.5 \mathrm{~h}$ ). At that point, we added the following drug combinations: a) untreated,

231 b) $5 \mathrm{mg} / 1 \mathrm{FLC}$, c) $5 \mathrm{mg} / 1 \mathrm{MPA}$, and d) $5 \mathrm{mg} / \mathrm{FLC}$ and $5 \mathrm{mg} / 1 \mathrm{MPA}$. The optimal concentrations

232 were determined with preliminary growth tests and checkerboard assays. All of the samples 233 received the same amount of DMSO.

234 At timepoints 0,2 , and $4 \mathrm{~h}$ we collected the samples with a 3 min spin down at 1,500 g, 4

$235{ }^{\circ} \mathrm{C}$, resuspended them in ice-cold water, and transferred them to $2 \mathrm{ml}$ screw caps, where we

236 performed a short spin down to remove the supernatant and froze the pellet in liquid nitrogen.

237 Samples were stored at $-80{ }^{\circ} \mathrm{C}$. Time points were determined according to growth curve assays,

238 Supplemental Files "Growth_curve_time_points_for_gene_expression.docx".

239 RNA isolation and qPCR analysis were performed as described previously (Tscherner et

240 al., 2012). PGK1 and RIPl were used as housekeeping genes (Hnisz et al., 2010; Li, Skinner \&

241 Bennett, 2012).

242 The primers used were CgPGK1f (5'-ACGAAGTTGTCAAGTCCTCCA-3'), CgPGK1r

243 (5'-TTACCTTCCAACAATTCCAAGGAG-3'), CgRIP1f (5'-

244 CTTCATGGTCGGTTCTCTAGG-3'), CgRIP1r (5'-ACAACAACGTTCTTACCCTCAG-3'), 
245 CgPDR1f (5'-TACCAATGTCTCAGATACCACCA-3'), CgPDR1r (5'-

246 CTGTCTTTAGAATCCAACTGCGT-3'), CgCDR1f (5'-

247 AGACTTACGCTAGACATTTAACGG-3'), and CgCDR1r (5'-

248 CACAAATAGAGACTTCAGCAATGG-3'). Amplification curves were analysed using the

249 Realplex Software (Eppendorf) and relative mRNA quantification was performed using the

250 efficiency corrected $\Delta \Delta \mathrm{Ct}$ method (Pfaffl, 2001). Quantification was performed in Excel

251 (Microsoft) and statistical analysis with GraphPad Prism (GraphPad Software) using one-way

252 ANOVA and Bonferroni's multiple comparison test.

253

254 Results

255 Drug susceptibility. Each test had MICs of the control strains (C. parapsilosis ATCC

25622019 , C. krusei ATCC 6258) within the expected range for the tested antifungal. MICs for

257 selected strains against individual drugs at $48 \mathrm{~h}$ are summarized in Table 2. Strains showed

258 resistance to certain antifungals; for example, Sc2 (32-64 mg/l), Cg5 (64-128 mg/l), and Cg6 (128

$259 \mathrm{mg} / \mathrm{l})$ against FLC and Sc1 (2 mg/l), Sc2 (2-4 mg/l), Sc3 (2-4 mg/l), Cg5 (4-16 mg/l), and Cg6

260 (128 mg/l) against ITC (CLSI, 2008). For most of the immunomodulatory drugs, the concentration

261 range that was used here, and was based on the range expected in human blood after drug

262 administration, did not obtain a MIC; exceptions were some strains with MPA (Sc3, Sc4, Sc5, Cg2

263 at $120 \mathrm{mg} / \mathrm{l})$ and Fk506 (Sc4, Sc6 at $200 \mathrm{mg} / \mathrm{l})$.

265 Table 2

266 

microdilution assay. A summary of the interpretations for each strain and drug combination is

269 found in Figure 1. The interaction was considered significant, if it was confirmed with at least one 270 model (FICI or BI). Calculated FICI and BI values are located in Supplemental Files 271 “Calculated_FICI_and_BI_values.xlsx”.

272 The FLC+MPA combination was antagonistic in 8 out of 12 strains (five S. cerevisiae, 273 three $C$. glabrata) and synergistic in two C. glabrata strains. One synergistic and two indifferent 274 interactions involved highly resistant strains (MIC of $64 \mathrm{mg} / \mathrm{l}$ or higher). The AMB+MPA 275 combination had a synergistic effect in 8 out of 12 strains (three $S$. cerevisiae, five $C$. glabrata) 276 and antagonism in one $S$. cerevisiae isolate. The effect of ITC+MPA was not as uniform; four 277 synergistic and three antagonistic interactions were observed, indicating that the response is strain278 specific.

A strain-specific response was observed in the combination of antifungals and MTX or 280 AMX as well. MTX+FLC had two synergistic and three antagonistic interactions, MTX+ITC four 281 synergistic and one antagonistic, MTX+AMB two synergistic and five antagonistic, AMX+FLC three synergistic interactions, $\mathrm{AMX}+\mathrm{ITC}$ two synergistic and one antagonistic, and $\mathrm{AMX}+\mathrm{AMB}$ five synergistic and four antagonistic interactions. were synergistic, even in the FLC and ITC resistant strains $\mathrm{Cg} 5$ and $\mathrm{Cg} 6$. Antagonistic interactions were observed only in the combination of CsA and FLC in three S. cerevisiae isolates.

The results from the FICI and BI models fitted well, and both showed a trend towards the same interpretation; if the interpretation with one model was synergy, the other model either showed synergy or indifference, but never the opposite, antagonism. Out of 180 combinations 
290 tested against selected strains, the FICI model showed 60 significant modulatory interactions and

291 the BI model 124, in which most of the absolute sum values ( $\Sigma$ SYN or $\Sigma$ ANT) indicated strong

292 interactions $(>200 \%)$.

293

294 Figure 1

295

296

297

ATCC 2001 was used to further explore the observed antagonism between MPA and azole 298 antifungals (Figure 2A). Azole antifungals included FLC, ITC, KCT, VRC, and POS. Table 3 shows the MIC, FICI, and BI of this strain against azole antifungals combined with MPA (MIC for MPA ranges from 32 to $64 \mathrm{mg} / \mathrm{l}$ ) in YPD at $37^{\circ} \mathrm{C}$ after 48 hours. All of the interactions were interpreted as antagonistic by at least one model. This confirms that an antagonistic interaction between MPA and all of the selected azole antifungals occurs in C. glabrata ATCC 2001.

Table 3

305

The roles of $P D R 1$ and $C D R 1$. Gene expression of $P D R 1$ and $C D R 1$ was analysed in $C$. glabrata ATCC 2001 at two different timepoints (Figure 2). It was calculated relative to the untreated samples for each timepoint. All of the following differences described have statistical significance $(\mathrm{p}$-value $<0.05)$.

311 higher than in all the other conditions, including the samples treated with the combination of 
312 FLC+MPA. At 4 hours the expression of PDRI was still higher in samples treated with FLC

313 compared to the untreated samples and samples treated with MPA.

314 For $C D R 1$, at 2 hours, all treated samples (FLC, MPA, FLC+MPA) had higher expression

315 than the untreated samples. At 2 hours FLC+MPA had higher expression of CDR1 than the FLC-

316 treated samples. At 4 hours the expression of $C D R 1$ was even higher in MPA and FLC+MPA-

317 treated samples and was significantly higher than in the samples treated only with FLC.

318 The expression patterns for $C D R 1$, which seemed like a good candidate to explain the

319 antagonism of the drug combination, and the low expression of PDRl in the MPA and FLC+MPA-

320 treated samples questioned whether the $P D R 1$ regulatory cascade has a central role in the drug

321 response mechanism responsible for antagonism between FLC and MPA. To test this, we

322 performed a checkerboard assay with $\operatorname{Cg} p d r 1 \Delta$ mutant against the combination of FLC and MPA.

323 Figure 2B shows the relative growth from this assay, in which we saw increased susceptibility to

324 FLC (MIC at $4 \mathrm{mg} / \mathrm{l}$ ) and the antagonistic pattern, which was confirmed by the BI model ( $\Sigma$ ANT

$325=-320.79 \%)$. These results suggest that the typical $P D R 1$ drug response is not the only pathway 326 required for this antagonistic interaction and that the induction of $C D R 1$ in this case could to be 327 regulated by alternative pathways.

328

329 Figure 2

330

331 Discussion

332 Drug combinations can present an attractive way to deal with antifungal resistance and the

333 lack of antifungals, but there may be dangerous complications when there are adverse reactions in

334 the host or antagonism between the drugs. In this study, the combination of MPA and FLC made 
335 eight out of twelve strains (five S. cerevisiae, three C. glabrata; all are less resistant strains) more

336 tolerant to the antifungal. This could have consequences in the clinical environment, and it also

337 opens a path to explore drug resistance mechanisms.

338 Synergism: calcineurin inhibitors + antifungals. Certain patterns were observed with

339 different drug combinations (Figure 1). The most striking one was a generally synergistic effect

340 between most antifungals and calcineurin inhibitors (CsA and Fk506) against all strains tested.

341 The synergistic effect of calcineurin inhibitors and antifungals is well documented (Cruz et al.,

342 2002; Li et al., 2015; Denardi et al., 2015; Yu, Chang \& Chen, 2015). Our results differ to those

343 of Cruz et. al., 2002 who reported synergistic toxicity toward other fungal species but not $S$.

344 cerevisiae. This may be due to a strain-specific response in S. cerevisiae, but further tests are

345 required to clarify this.

Antagonism: MPA + azoles. Eight out of twelve antagonistic interactions between MPA

347 and FLC were found. Antagonism was not observed in strains that had high resistance to FLC (Sc2

$34832-64 \mathrm{mg} / \mathrm{l}, \mathrm{Cg} 564-128 \mathrm{mg} / \mathrm{l}$, and $\mathrm{Cg} 6128 \mathrm{mg} / \mathrm{l}$ ), which indicates that the antagonism is probably

349 the result of similar mechanisms that produce the high resistance. FLC resistance mechanisms

350 include overexpression of the efflux pumps in most cases (Whaley \& Rogers, 2016). The

351 antifungal activity of MPA, which is due to the depletion of purine nucleotides (Banerjee, Burkard

352 \& Panepinto, 2014), made the antagonistic effect all the more surprising. We therefore explored

353 whether the most common mechanism of azole resistance in C. glabrata and S. cerevisiae (Pdr1

354 induction of efflux pump Cdr1/Pdr5) had a role in this antagonistic interaction.

355 Antagonism: the roles of PDR1 and CDR1. The central role of the transcriptional factor

356 Pdr1 in azole resistance has been described in detail (Caudle et al., 2011; Yibmantasiri et al., 2014).

357 It is usually linked to the induction of efflux pumps (Cdr1 as a dominant example) that remove the 
358 azole antifungals from the cell. In this study, relatively high expression values of $C D R 1$ were

359 observed in the drug combination FLC+MPA and MPA alone compared to the untreated samples

360 and even to the FLC-treated ones (Figure 2D). This makes the induction of efflux pumps a good

361 explanation for the increased resistance to azole antifungals. However, an interesting aspect arose

362 when examining the expression values of PDR1 (Figure 2C) because their expression pattern did

363 not match the $C D R 1$ induction. Normally, Pdr1 positively regulates the expression of $C D R 1$, but

364 this was not seen here. This suggests that Pdr1 is not the only regulatory mechanism enabling a

365 higher expression of CDRI with MPA or the FLC+MPA combination. This was further

366 demonstrated by an antagonistic effect in the Cgpdr $1 \Delta$ mutant, interpreted by the BI model with a

$367 \Sigma$ ANT value of $-320.79 \%$, although at lower concentrations of FLC (Figure 2B). Undoubtedly

368 Pdr1 still plays a major role in overall resistance (because resistance to FLC did drop in the

369 combination versus $\operatorname{Cg} p d r 1 \Delta)$, but the antagonistic pattern still existed. This opens up new and

370 interesting questions regarding which mechanisms instead of the Pdr1 regulatory cascade are

371 responsible for higher $C D R 1$ expression and the observed antagonistic effect. Alternative

372 regulators of $C D R 1$ could include transcriptional factors associated with multidrug resistance (e.g.,

$373 R D R 1, Y R R 1, Y R M 1$, and STB5) or CAD1, MSN2, and MSN4 for general stress response, YAP1 for

374 oxidative stress, $C R Z 1$ from calcineurin-mediated stress response, or ECM22 and UPC2 for cell

375 membrane composition (Monteiro et al., 2017; Teixeira et al., 2018). In addition to Cdr1, other

376 efflux pumps associated with azole resistance should also be considered in the future, such as Cdr2

377 (Miyazaki et al., 1998), Snq2 (Torelli et al., 2008), Flr1 (Alarco et al., 1997), Qdr2 (Costa et al.,

378 2013), Tpo1_2 (Pais et al., 2016), Ybt1 (Tsai et al., 2010), Yhk8 (Barker, Pearson \& Rogers, 2003)

379 and Yor1 (Vermitsky et al., 2006). Further studies at the systemic level would be required to obtain

380 a better picture of the entire mechanism. 
Antagonism: clinical environment. There are clinical implications to this discovery.

382 MPA (and its prodrug mycophenolate mofetil) is widely used as a maintenance

383 immunosuppressive regimen in solid organ transplant patients, for the prophylaxis and treatment

384 of acute and chronic graft-versus-host disease, and to promote engraftment after hematopoietic

385 stem cell transplantation (Zhang \& Chow, 2016). There is no data on the frequency of clinical

386 usage for the combination of FLC+MPA; however, antifungal prophylaxis with azoles (VRC,

387 POS, ITC, and FLC) is commonly prescribed in immunocompromised populations, which also

388 involve the use of MPA (Pappas \& Silveira, 2009; Brizendine, Vishin \& Baddley, 2011; Groll et

389 al., 2014). Possible antifungal prophylaxis or actual treatments with azole antifungals in these

390 cases should therefore be used with caution and considered for each individual case because

391 induced resistance could result in a failed therapy. There is even a report of a statistically

392 significant increase in fungal infections in the geriatric renal transplant population when receiving

393 MPA versus azathioprine, but the specific organisms and sites of infection were not reported

394 (Meier-Kriesche et al., 1999; Ritter \& Pirofski, 2009). It can be speculated that this antagonism

395 could be connected to this increase in fungal infections, because FLC and other azoles (VRC, POS

396 and ITR) are used for the prophylaxis in solid organ transplantations and other therapies involving

397 immunocompromised patients (Pappas \& Silveira, 2009; Brizendine, Vishin \& Baddley, 2011;

398 Groll et al., 2014; Vazquez, 2016). The next steps should expand the number of tested strains and

399 species against the combination of azoles and MPA, include an in vivo evaluation of the 400 combination, and include other drugs involved in a certain therapy as well; for example, a typical

401 cocktail of prednisolone, MPA, and cyclosporine in solid organ transplantations (Sollinger, 1995).

402

403 Conclusion 

selected strains of $C$. glabrata and $S$. cerevisiae. It confirmed a strong synergistic toxicity between calcineurin inhibitors and antifungals, but also discovered an antagonistic interaction between MPA and azoles in non-resistant strains. Based on observation of gene expression in C. glabrata ATCC 2001 this is probably due to increased expression of drug efflux pump Cdr1 by MPA. However, the mechanism of the induction is still unknown because the Pdr1 regulatory cascade was not essential for the antagonistic interaction, and this deserves further investigation. In addition, the combined use of MPA and azoles in the clinical environment should be carefully

412 reevaluated. In particular, there is a need to recognize that drug combinations affect not only the 413 host but also the pathogen.

\section{Acknowledgement}

416 We thank Neža Čadež, the curator of the Collection of Industrial Microorganisms (ZIM) at the

417 Biotechnical Faculty, Slovenia, for providing us with the yeast strains; and Karl Kuchler from the 418 Medical University of Vienna and his team of researchers for helping with the technical part of the 419 qPCR analysis and for providing the Cgpdr1s mutant. We also thank the company Acies Bio, 420 which provided the drug Fk506.

\section{References}

Adams A., Gottschling D., Kaiser C., Stearns T. 1998. Methods in Yeast Genetics: a Laboratory Course Manual. New York: Cold Spring Harbor Laboratory Press, Cold Spring Harbor, NY. 
426 Alarco AM., Balan I., Talibi D., Mainville N., Raymond M. 1997. Ap1-mediated multidrug

427 resistance in saccharomyces cerevisiae requires FLR1 encoding a transporter of the major

428 facilitator superfamily. Journal of Biological Chemistry 272:19304-19313. DOI:

$429 \quad 10.1074 / \mathrm{jbc} .272 .31 .19304$.

430

431

432

433

434

435

436

437

438

439

440

441

442

443

444

445

446

447

Alexander BD., Johnson MD., Pfeiffer CD., Jiménez-Ortigosa C., Catania J., Booker R., Castanheira M., Messer SA., Perlin DS., Pfaller M a. 2013. Increasing echinocandin resistance in candida glabrata: Clinical failure correlates with presence of FKS mutations and elevated minimum inhibitory concentrations. Clinical Infectious Diseases 56:17241732. DOI: $10.1093 /$ cid/cit136.

Aucott JN., Fayen J., Grossnicklas H., Morrissey A., Lederman MM., Salata RA. 1990. Invasive infection with Saccharomyces cerevisiae: Report of three cases and review. Clinical Infectious Diseases 12:406-411. DOI: 10.1093/clinids/12.3.406.

Banerjee D., Burkard L., Panepinto JC. 2014. Inhibition of nucleotide biosynthesis potentiates the antifungal activity of Amphotericin B. PloS one 9:e87246. DOI: 10.1371/journal.pone.0087246.

Barchiesi F., Arzeni D., Caselli F., Scalise G. 2000. Primary resistance to flucytosine among clinical isolates of Candida spp. J Antimicrob Chemother 45:408-409.

Barker KS., Pearson MM., Rogers PD. 2003. Identification of genes differentially expressed in association with reduced azole susceptibility in Saccharomyces cerevisiae. Journal of Antimicrobial Chemotherapy 51:1131-1140. DOI: 10.1093/jac/dkg217.

Berrouane YF., Herwaldt LA., Pfaller MA. 1999. Trends in antifungal use and epidemiology of nosocomial yeast infections in a University Hospital. Journal of Clinical Microbiology 
Bliss CI. 1939. THE TOXICITY OF POISONS APPLIED JOINTLY. Annals of Applied Biology 26:585-615. DOI: 10.1111/j.1744-7348.1939.tb06990.x.

Bollenbach T. 2015. Antimicrobial interactions: Mechanisms and implications for drug discovery and resistance evolution. Current Opinion in Microbiology 27:1-9. DOI: 10.1016/j.mib.2015.05.008.

Bolotin-Fukuhara M., Fairhead C. 2014. Candida glabrata: a deadly companion? Yeast (Chichester, England) 31:279-88. DOI: 10.1002/yea.3019.

Brizendine KD., Vishin S., Baddley JW. 2011. Antifungal prophylaxis in solid organ transplant recipients. Expert Review of Anti-infective Therapy 9:571-581. DOI: 10.1586/eri.11.29.

Brun S., Bergès T., Poupard P., Vauzelle-Moreau C., Renier G., Chabasse D., Bouchara J-PP., Bergés T., Poupard P., Vauzelle-Moreau C., Renier G., Chabasse D., Bouchara J-PP. 2004. Mechanisms of Azole Resistance in Petite Mutants of Candida glabrata. Antimicrobial agents and chemotherapy 48:1788-96. DOI: 10.1128/AAC.48.5.1788-1796.2004.

Cassone M., Serra P., Mondello F., Girolamo A., Scafetti S., Pistella E., Venditti M. 2003. Outbreak of Saccharomyces cerevisiae Subtype boulardii Fungemia in Patients Neighboring Those Treated with a Probiotic Preparation of the Organism. Journal of Clinical Microbiology 41:5340-5343. DOI: 10.1128/JCM.41.11.5340-5343.2003.

Caudle KE., Barker KS., Wiederhold NP., Xu L., Homayouni R., Rogers PD. 2011. Genomewide expression profile analysis of the Candida glabrata Pdr1 regulon. Eukaryotic cell 10:373-383. DOI: 10.1128/EC.00073-10. 
469 CLSI. 2008. Reference method for broth dilution antifungal susceptibility testing of yeasts;

470 Approved standard, 3rd ed, CLSI document M27-A3. Clinical and Laboratory Standards $471 \quad$ Institute (CLSI), Wayne, PA.

472 Colombo AL., Júnior JNDA., Guinea J. 2017. Emerging multidrug-resistant Candida species. $473 \quad$ Current Opinion in Infectious Diseases 30:528-538. DOI:

$474 \quad 10.1097 / \mathrm{QCO} .0000000000000411$.

475 Costa C., Pires C., Cabrito TR., Renaudin A., Ohno M., Chibana H., Sá-Correia I., Teixeira MC. 476 2013. Candida glabrata drug: $\mathrm{H}+$ antiporter CgQdr2 confers imidazole drug resistance, 477 being activated by transcription factor CgPdr1. Antimicrobial Agents and Chemotherapy $478 \quad 57: 3159-3167$. DOI: 10.1128/AAC.00811-12.

479 Cowen LE. 2008. The evolution of fungal drug resistance: Modulating the trajectory from 480 genotype to phenotype. Nature Reviews Microbiology 6:187-198. DOI:

481 10.1038/nrmicro1835.

482 Cowen LE. 2013. The fungal Achilles' heel: Targeting Hsp90 to cripple fungal pathogens. 483 Current Opinion in Microbiology 16:377-384. DOI: 10.1016/j.mib.2013.03.005.

Cruz MC., Goldstein AL., Blankenship JR., Del Poeta M., Davis D., Cardenas ME., Perfect JR., 485 McCusker JH., Heitman J. 2002. Calcineurin is essential for survival during membrane stress in Candida albicans. EMBO Journal 21:546-559. DOI: 10.1093/emboj/21.4.546.

Cui J., Ren B., Tong Y., Dai H., Zhang L. 2015. Synergistic combinations of antifungals and 488 anti-virulence agents to fight against Candida albicans. Virulence 6:362-371. DOI: 10.1080/21505594.2015.1039885. 
490 Denardi LB., Mario DAN., Loreto ÉS., Santurio JM., Alves SH. 2015. Synergistic effects of 491 tacrolimus and azole antifungal compounds in fluconazole-susceptible and fluconazole492 resistant Candida glabrata isolates. Brazilian Journal of Microbiology 46:125-129. DOI: 10.1590/S1517-838246120120442.

494 495

496

497

498

499

500 501

502 503 504

Enache-Angoulvant A., Hennequin C. 2005. Invasive Saccharomyces infection: a comprehensive review. Clinical infectious diseases : an official publication of the Infectious Diseases Society of America 41:1559-1568. DOI: 10.1086/497832.

Ghannoum MA., Elewski B. 1999. Successful treatment of fluconazole-resistant oropharyngeal candidiasis by a combination of fluconazole and terbinafine. Clinical and diagnostic laboratory immunology 6:921-3.

Glöckner A., Cornely OA. 2015. Candida glabrata - unique features and challenges in the clinical management of invasive infections. Mycoses 58:445-450. DOI: 10.1111/myc.12348.

Goldoni M., Johansson C. 2007. A mathematical approach to study combined effects of toxicants in vitro: Evaluation of the Bliss independence criterion and the Loewe additivity model. Toxicology in Vitro 21:759-769. DOI: 10.1016/j.tiv.2007.03.003.

Groll AH., Castagnola E., Cesaro S., Dalle JH., Engelhard D., Hope W., Roilides E., Styczynski J., Warris A., Lehrnbecher T. 2014. Fourth European Conference on Infections in Leukaemia (ECIL-4): Guidelines for diagnosis, prevention, and treatment of invasive fungal diseases in paediatric patients with cancer or allogeneic haemopoietic stem-cell transplantation. The Lancet Oncology 15:e327-e340. DOI: 10.1016/S1470-2045(14)700178.

Hachem R., Hanna H., Kontoyiannis D., Jiang Y., Raad I. 2008. The changing epidemiology of 
512 invasive candidiasis: Candida glabrata and candida krusei as the leading causes of

513 candidemia in hematologic malignancy. Cancer 112:2493-2499. DOI: 10.1002/cncr.23466.

514 Henry KW., Cruz MC., Katiyar SK., Edlind TD. 1999. Antagonism of azole activity against

515 Candida albicans following induction of multidrug resistance genes by selected

516 antimicrobial agents. Antimicrobial Agents and Chemotherapy 43:1968-1974.

517 Hnisz D., Majer O., Frohner IE., Komnenovic V., Kuchler K. 2010. The set3/Hos2 histone

518 deacetylase complex attenuates camp/pka signaling to regulate morphogenesis and

519 virulence of candida albicans. PLoS Pathogens 6:1-18. DOI: 10.1371/journal.ppat.1000889.

520 Khatib R., Johnson LB., Fakih MG., Riederer K., Briski L. 2016. Current trends in candidemia

521 and species distribution among adults: Candida glabrata surpasses C. albicans in diabetic

522 patients and abdominal sources. Mycoses 59:781-786. DOI: 10.1111/myc.12531.

523 Kontoyiannis DP. 2000. Modulation of fluconazole sensitivity by the interaction of mitochondria

524 and erg3p in Saccharomyces cerevisiae. The Journal of antimicrobial chemotherapy

525 46:191-7. DOI: 10.1093/jac/46.2.191.

526 LaFayette SL., Collins C., Zaas AK., Schell WA., Betancourt-Quiroz M., Leslie Gunatilaka AA.,

527 Perfect JR., Cowen LE., Gunatilaka AAL., Perfect JR., Cowen LE., Leslie Gunatilaka AA.,

528 Perfect JR., Cowen LE., Gunatilaka AAL., Perfect JR., Cowen LE. 2010. PKC signaling

529 regulates drug resistance of the fungal pathogen candida albicans via circuitry comprised of

$530 \quad \mathrm{mkc1}$, calcineurin, and hsp90. PLoS Pathogens 6:e1001069. DOI:

$531 \quad$ 10.1371/journal.ppat.1001069.

532 Lherm T., Monet C., Nougière B., Soulier M., Larbi D., Le Gall C., Caen D., Malbrunot C. 2002.

533 Seven cases of fungemia with Saccharomyces boulardii in critically ill patients. Intensive 
535 Li H., Chen Z., Zhang C., Gao Y., Zhang X., Sun S. 2015. Resistance reversal induced by a 536 combination of fluconazole and tacrolimus (FK506) in Candida glabrata. Journal of Medical Microbiology 64:44-52. DOI: 10.1099/jmm.0.081760-0.

538

539

540

541

542

543

544

545

546

547

548

549

550

551

552

553

554

Li QQ., Skinner J., Bennett JE. 2012. Evaluation of reference genes for real-time quantitative PCR studies in Candida glabrata following azole treatment. BMC Molecular Biology 13:22. DOI: $10.1186 / 1471-2199-13-22$.

Liguori G., Di Onofrio V., Lucariello A., Gallé F., Signoriello G., Colella G., D’Amora M., Rossano F. 2009. Oral candidiasis: a comparison between conventional methods and multiplex polymerase chain reaction for species identification. Oral microbiology and immunology 24:76-8. DOI: 10.1111/j.1399-302X.2008.00447.x.

Liu S., Hou Y., Chen X., Gao Y., Li H., Sun S. 2014. Combination of fluconazole with nonantifungal agents: a promising approach to cope with resistant Candida albicans infections and insight into new antifungal agent discovery. International journal of antimicrobial agents 43:395-402. DOI: 10.1016/j.ijantimicag.2013.12.009.

Loewe S. 1928. Die quantitativen Probleme der Pharmakologie. Ergebnisse der Physiologie 27:47-187. DOI: 10.1007/BF02322290.

Meier-Kriesche HU., Friedman G., Jacobs M., Mulgaonkar S., Vaghela M., Kaplan B. 1999. Infectious complications in geriatric renal transplant patients: comparison of two immunosuppressive protocols. Transplantation 68:1496-502.

Meletiadis J., Verweij PE., TeDorsthorst DT a., Meis JFGM., Mouton JW., Te Dorsthorst DTA., 
555

556

557

558

559

560

561

562

563

564

565

566

567

568

569

570

571

572

573

574

575

576

Meis JFGM., Mouton JW. 2005. Assessing in vitro combinations of antifungal drugs against yeasts and filamentous fungi: comparison of different drug interaction models. Medical mycology : official publication of the International Society for Human and Animal Mycology 43:133-152. DOI: 10.1080/13693780410001731547.

Miyazaki H., Miyazaki Y., Geber A., Parkinson T., Hitchcock C., Falconer DJ., Ward DJ., Marsden K., Bennett JE. 1998. Fluconazole resistance associated with drug efflux and increased transcription of a drug transporter gene, PDH1, in Candida glabrata. Antimicrobial agents and chemotherapy 42:1695-1701.

Monteiro PT., Pais P., Costa C., Manna S., Sa-Correia I., Teixeira MC. 2017. The PathoYeastract database: An information system for the analysis of gene and genomic transcription regulation in pathogenic yeasts. Nucleic Acids Research 45:D597-D603. DOI: $10.1093 / \mathrm{nar} / \mathrm{gkw} 817$.

Moody J. 2010. Synergism Testing: Broth Microdilution Checkerboard and Broth Macrodilution Methods. In: Garcia L ed. Clinical Microbiology Procedures Handbook, 3rd Edition. American Society of Microbiology, 140-162.

Morio F., Pagniez F., Lacroix C., Miegeville M., Le pape P. 2012. Amino acid substitutions in the Candida albicans sterol $\delta 5,6$-desaturase (Erg3p) confer azole resistance: Characterization of two novel mutants with impaired virulence. Journal of Antimicrobial Chemotherapy 67:2131-2138. DOI: 10.1093/jac/dks186.

Moye-Rowley WS. 2003. Transcriptional Control of Multidrug Resistance in the Yeast Saccharomyces. Progress in Nucleic Acid Research and Molecular Biology 73:251-279. DOI: $10.1016 / \mathrm{S} 0079-6603(03) 01008-0$. 
577 Murphy A., Kavanagh K. 1999. Emergence of Saccharomyces cerevisiae as a human pathogen

578 Implications for biotechnology. Enzyme and Microbial Technology 25:551-557. DOI:

579 10.1016/S0141-0229(99)00086-1.

580

581

582

583

584

585

586

587

588

589

590

591

592

593

594

595

596

597

598

Nagi M., Nakayama H., Tanabe K., Bard M., Aoyama T., Okano M., Higashi S., Ueno K., Chibana H., Niimi M., Yamagoe S., Umeyama T., Kajiwara S., Ohno H., Miyazaki Y. 2011. Transcription factors $\mathrm{CgUPC} 2 \mathrm{~A}$ and $\mathrm{CgUPC} 2 \mathrm{~B}$ regulate ergosterol biosynthetic genes in Candida glabrata. Genes to Cells 16:80-89. DOI: 10.1111/j.13652443.2010.01470.x.

Nakayama H., Tanabe K., Bard M., Hodgson W., Wu S., Takemori D., Aoyama T., Kumaraswami NS., Metzler L., Takano Y., Chibana H., Niimi M., Kumaraswami SN., Metzler L., Takano Y., Chibana H., Niimi M. 2007. The Candida glabrata putative sterol transporter gene CgAUS1 protects cells against azoles in the presence of serum. Journal of Antimicrobial Chemotherapy 60:1264-1272. DOI: 10.1093/jac/dkm321.

Navarro-Martínez MD., Cabezas-Herrera J., Rodríguez-López JN. 2006. Antifolates as antimycotics?. Connection between the folic acid cycle and the ergosterol biosynthesis pathway in Candida albicans. International Journal of Antimicrobial Agents 28:560-567.

DOI: 10.1016/j.jjantimicag.2006.07.012.

Nett JE., Andes DR. 2016. Antifungal Agents: Spectrum of Activity, Pharmacology, and Clinical Indications. Infectious Disease Clinics of North America 30:51-83. DOI: 10.1016/j.idc.2015.10.012.

Odds FC. 2003. Synergy, antagonism, and what the chequerboard puts between them. The Journal of antimicrobial chemotherapy 52:1. DOI: 10.1093/jac/dkg301. 
599 Pachl J., Svoboda P., Jacobs F., Vandewoude K., van der Hoven B., Spronk P., Masterson G., 600 Malbrain M., Aoun M., Garbino J., Takala J., Drgona L., Burnie J., Matthews R. 2006. A 601 Randomized, Blinded, Multicenter Trial of Lipid-Associated Amphotericin B Alone versus 602 in Combination with an Antibody-Based Inhibitor of Heat Shock Protein 90 in Patients with 603 Invasive Candidiasis. Clinical Infectious Diseases 42:1404-1413. DOI: 10.1086/503428.

604 Pais P., Costa C., Pires C., Shimizu K., Chibana H., Teixeira MC. 2016. Membrane Proteome605 Wide Response to the Antifungal Drug Clotrimazole in Candida glabrata: Role of the 606 Transcription Factor CgPdr1 and the Drug:H+ Antiporters CgTpo1_1 and CgTpo1_2. 607 Molecular \& cellular proteomics : MCP 15:57-72. DOI: 10.1074/mcp.M114.045344. 608 Pappas PG., Kauffman CA., Andes DR., Clancy CJ., Marr KA., Ostrosky-Zeichner L., Reboli 609 AC., Schuster MG., Vazquez JA., Walsh TJ., Zaoutis TE., Sobel JD. 2015. Clinical Practice 610 Guideline for the Management of Candidiasis: 2016 Update by the Infectious Diseases 611 Society of America. Clinical Infectious Diseases 62:e1-e50. DOI: 10.1093/cid/civ933.

612 Pappas PG., Silveira FP. 2009. Candida in solid organ transplant recipients. American Journal of 613 Transplantation 9:S173-S179. DOI: 10.1111/j.1600-6143.2009.02909.x.

614 Pfaller MA. 2012. Antifungal drug resistance: mechanisms, epidemiology, and consequences for 615 treatment. The American journal of medicine 125:S3-13. DOI:

$616 \quad$ 10.1016/j.amjmed.2011.11.001.

617 Pfaller MA., Andes DR., Diekema DJ., Horn DL., Reboli AC., Rotstein C., Franks B., Azie NE.

618 2014. Epidemiology and outcomes of invasive candidiasis due to non-albicans species of 619 Candida in 2,496 patients: Data from the Prospective Antifungal Therapy (PATH) registry 620 2004-2008. PLoS ONE 9:e101510. DOI: 10.1371/journal.pone.0101510. 
621 Pfaller MA., Castanheira M. 2016. Nosocomial candidiasis: Antifungal stewardship and the 622 importance of rapid diagnosis. Medical Mycology 54:1-22. DOI: 10.1093/mmy/myv076.

623 Pfaller MA., Castanheira M., Lockhart SR., Jones RN. 2012a. Candida glabrata: Multidrug 624 resistance and increased virulence in a major opportunistic fungal pathogen. Current Fungal 625 Infection Reports 6:154-164. DOI: 10.1007/s12281-012-0091-0.

626 Pfaller MA., Diekema DJ. 2007. Epidemiology of invasive candidiasis: A persistent public 627 health problem. Clinical Microbiology Reviews 20:133-163. DOI: 10.1128/CMR.00029-06.

628 Pfaller MA., Diekema DJ. 2010. Epidemiology of invasive mycoses in North America. Critical 629 Reviews in Microbiology 36:1-53. DOI: 10.3109/10408410903241444.

630 Pfaller M., Neofytos D., Diekema D., Azie N., Meier-Kriesche HU., Quan SP., Horn D. 2012 b. 631 Epidemiology and outcomes of candidemia in 3648 patients: Data from the Prospective 632 Antifungal Therapy (PATH Alliance??) registry, 2004-2008. Diagnostic Microbiology and 633 Infectious Disease 74:323-331. DOI: 10.1016/j.diagmicrobio.2012.10.003.

634 Pfaffl MW. 2001. A new mathematical model for relative quantification in real-time RT-PCR. $635 \quad$ Nucleic Acids Research 29:e45.

636 Piarroux R., Millon L., Bardonnet K., Vagner O., Koenig H. 1999. Are live saccharomyces 637 yeasts harmful to patients? Lancet 353:1851-1852. DOI: 10.1016/S0140-6736(99)02001-2.

638 Rex JH., Pappas PG., Karchmer AW., Sobel J., Edwards JE., Hadley S., Brass C., Vazquez JA., 639 Chapman SW., Horowitz HW., Zervos M., McKinsey D., Lee J., Babinchak T., Bradsher 640 RW., Cleary JD., Cohen DM., Danziger L., Goldman M., Goodman J., Hilton E., Hyslop 641 NE., Kett DH., Lutz J., Rubin RH., Scheld WM., Schuster M., Simmons B., Stein DK., 
642 Washburn RG., Mautner L., Chu T., Panzer H., Rosenstein RB., Booth J. 2003. A

643 Randomized and Blinded Multicenter Trial of High-Dose Fluconazole plus Placebo versus

644 Fluconazole plus Amphotericin B as Therapy for Candidemia and Its Consequences in

645 Nonneutropenic Subjects. Clinical Infectious Diseases 36:1221-1228. DOI:

$646 \quad 10.1086 / 374850$.

647 Ritter ML., Pirofski L. 2009. Mycophenolate mofetil: effects on cellular immune subsets, 648 infectious complications, and antimicrobial activity. Transplant infectious disease : an 649 official journal of the Transplantation Society 11:290-297. DOI: 10.1111/j.1399$650 \quad 3062.2009 .00407 . x$

651 Roetzer A., Gabaldón T., Schüller C. 2011. From Saccharomyces cerevisiae to Candida 652 glabratain a few easy steps: important adaptations for an opportunistic pathogen. FEMS 653 microbiology letters 314:1-9. DOI: 10.1111/j.1574-6968.2010.02102.x.

654 Roy U., Jessani LG., Rudramurthy SM., Gopalakrishnan R., Dutta S., Chakravarty C., Jillwin J., 655 Chakrabarti A. 2017. Seven cases of Saccharomyces fungaemia related to use of probiotics. $656 \quad$ Mycoses. DOI: $10.1111 /$ myc.12604.

657 Sanglard D., Ischer F., Bille J. 2001. Role of ATP-binding-cassette transporter genes in high658 frequency acquisition of resistance to azole antifungals in Candida glabrata. Antimicrobial 659 agents and chemotherapy 45:1174-83. DOI: 10.1128/AAC.45.4.1174-1183.2001.

660 Sanguinetti M., Posteraro B., Fiori B., Ranno S., Torelli R., Fadda G. 2005. Mechanisms of azole 661 resistance in clinical isolates of Candida glabrata collected during a hospital survey of 662 antifungal resistance. Antimicrobial Agents and Chemotherapy 49:668-679. DOI:

$663 \quad$ 10.1128/AAC.49.2.668-679.2005. 
664 Scheven M., Junemann K., Schramm H., Huhn W. 1992. Successful treatment of a Candida 665 albicans sepsis with a combination of flucytosine and fluconazole. Mycoses 35:315-316. 666 DOI: 10.1111/j.1439-0507.1992.tb00886.x.

667 Schwarzmüller T., Ma B., Hiller E., Istel F., Tscherner M., Brunke S., Ames L., Firon A., Green 668 B., Cabral V., Marcet-Houben M., Jacobsen ID., Quintin J., Seider K., Frohner I., Glaser 669 W., Jungwirth H., Bachellier-Bassi S., Chauvel M., Zeidler U., Ferrandon D., Gabaldón T., 670 Hube B., D’Enfert C., Rupp S., Cormack B., Haynes K., Kuchler K. 2014. Systematic 671 phenotyping of a large-scale Candida glabrata deletion collection reveals novel antifungal 672 tolerance genes. PLoS pathogens 10:e1004211. DOI: 10.1371/journal.ppat.1004211.

673 Segireddy M., Johnson LB., Szpunar SM., Khatib R. 2011. Differences in patient risk factors and 674 source of candidaemia caused by Candida albicans and Candida glabrata. Mycoses 54:e39675 e43. DOI: 10.1111/j.1439-0507.2009.01824.x.

Shah CP., Kharkar PS. 2015. Inosine 5'-monophosphate dehydrogenase inhibitors as antimicrobial agents: recent progress and future perspectives. Future Medicinal Chemistry 7:1415-1429. DOI: $10.4155 / \mathrm{fmc} .15 .72$.

679

680

681

682

683

684

685

Silva S., Negri M., Henriques M., Oliveira R., Williams DW., Azeredo J. 2012. Candida glabrata, Candida parapsilosis and Candida tropicalis: Biology, epidemiology, pathogenicity and antifungal resistance. FEMS Microbiology Reviews 36:288-305. DOI: 10.1111/j.15746976.2011.00278.x.

Sollinger HW. 1995. Mycophenolate mofetil for the prevention of acute rejection in primary cadaveric renal allograft recipients. U.S. Renal Transplant Mycophenolate Mofetil Study Group. Transplantation 60:225-32. DOI: 10.1097/00007890-199508000-00003. 
686 Steinbach WJ., Reedy JL., Cramer RA., Perfect JR., Heitman J. 2007. Harnessing calcineurin as

687 a novel anti-infective agent against invasive fungal infections. Nature Reviews

688 Microbiology 5:418-30. DOI: 10.1038/nrmicro1680.

689 Svetaz LA., Postigo A., Butassi E., Zacchino SA., Sortino MA. 2016. Antifungal drugs

690 combinations: a patent review 2000-2015. Expert Opinion on Therapeutic Patents 26:439-

691 453. DOI: $10.1517 / 13543776.2016 .1146693$.

692 Teixeira MC., Monteiro PT., Palma M., Costa C., Godinho CP., Pais P., Cavalheiro M., Antunes

693 M., Lemos A., Pedreira T., Sá-Correia I. 2018. YEASTRACT: An upgraded database for

694 the analysis of transcription regulatory networks in Saccharomyces cerevisiae. Nucleic

695 Acids Research 46:D348-D353. DOI: 10.1093/nar/gkx842.

696 Torelli R., Posteraro B., Ferrari S., La Sorda M., Fadda G., Sanglard D., Sanguinetti M. 2008.

697 The ATP-binding cassette transporter-encoding gene CgSNQ2 is contributing to the

698 CgPDR1-dependent azole resistance of Candida glabrata. Molecular microbiology 68:186-

699 201. DOI: $10.1111 /$ j.1365-2958.2008.06143.x.

700 Tsai HF., Krol AA., Sarti KE., Bennett JE. 2006. Candida glabrata PDR1, a transcriptional

701 regulator of a pleiotropic drug resistance network, mediates azole resistance in clinical

702 isolates and petite mutants. Antimicrobial Agents and Chemotherapy 50:1384-1392. DOI:

$703 \quad$ 10.1128/AAC.50.4.1384-1392.2006.

704 Tsai H-FF., Sammons LR., Zhang X., Suffis SD., Su Q., Myers TG., Marr KA., Bennett JE.

705 2010. Microarray and molecular analyses of the azole resistance mechanism in Candida

706 glabrata oropharyngeal isolates. Antimicrobial Agents and Chemotherapy 54:3308-3317.

707 DOI: $10.1128 /$ AAC.00535-10. 
708 Tscherner M., Stappler E., Hnisz D., Kuchler K. 2012. The histone acetyltransferase Hat1 709 facilitates DNA damage repair and morphogenesis in Candida albicans. Molecular $710 \quad$ Microbiology 86:1197-1214. DOI: 10.1111/mmi.12051.

711 Vazquez L. 2016. Antifungal prophylaxis in immunocompromised patients. Mediterranean 712 Journal of Hematology and Infectious Diseases 8:e2016040. DOI:

$713 \quad$ 10.4084/MJHID.2016.040.

714 Veri A., Cowen LE. 2014. Progress and prospects for targeting Hsp90 to treat fungal infections. 715 Parasitology 141:1127-1137. DOI: 10.1017/S0031182013002072.

716 Vermitsky J-P., Earhart KD., Smith WL., Homayouni R., Edlind TD., Rogers PD. 2006. Pdr1

717 regulates multidrug resistance in Candida glabrata: gene disruption and genome-wide 718 expression studies. Molecular microbiology 61:704-22. DOI: 10.1111/j.1365$719 \quad 2958.2006 .05235 . x$.

720 Vermitsky JP., Edlind TD. 2004. Azole resistance in Candida glabrata: Coordinate upregulation 721 of multidrug transporters and evidence for a Pdr1-like transcription factor. Antimicrobial 722 Agents and Chemotherapy 48:3773-3781. DOI: 10.1128/AAC.48.10.3773-3781.2004.

723 Whaley SG., Berkow EL., Rybak JM., Nishimoto AT., Barker KS., Rogers PD. 2017. Azole

724 Antifungal Resistance in Candida albicans and Emerging Non-albicans Candida Species. $725 \quad$ Frontiers in Microbiology 7:2173. DOI: 10.3389/fmicb.2016.02173.

726 Whaley SG., Rogers PD. 2016. Azole Resistance in Candida glabrata. Current Infectious 727 Disease Reports 18:41. DOI: 10.1007/s11908-016-0554-5.

728 Wheeler RT., Kupiec M., Magnelli P., Abeijon C., Fink GR. 2003. A Saccharomyces cerevisiae 
mutant with increased virulence. Proceedings of the National Academy of Sciences of the United States of America 100:2766-70. DOI: 10.1073/pnas.0437995100.

731 732

733

734

735

736

Yeh PJ., Hegreness MJ., Aiden AP., Kishony R. 2009. Drug interactions and the evolution of antibiotic resistance. Nature Reviews Microbiology 7:460-466. DOI: 10.1038/nrmicro2133.

Yibmantasiri P., Bircham PW., Maass DR., Bellows DS., Atkinson PH. 2014. Networks of genes modulating the pleiotropic drug response in Saccharomyces cerevisiae. Mol. BioSyst.

$$
\text { 10:128-137. DOI: 10.1039/C3MB70351G. }
$$

Yu SJ., Chang YL., Chen YL. 2015. Calcineurin signaling: Lessons from Candida species. FEMS Yeast Research 15:fov016. DOI: 10.1093/femsyr/fov016.

Zhang D., Chow DS-L. 2016. Clinical pharmacokinetics of mycophenolic acid in hematopoietic stem cell transplantation recipients. European Journal of Drug Metabolism and Pharmacokinetics 42:1-7. DOI: 10.1007/s13318-016-0378-6.

Zupan J., Avbelj M., Butinar B., Kosel J., Šergan M., Raspor P. 2013. Monitoring of quorumsensing molecules during minifermentation studies in wine yeast. In: Journal of Agricultural and Food Chemistry. 2496-2505. DOI: 10.1021/jf3051363. 


\section{Table $\mathbf{1}$ (on next page)}

Clinical isolates and their source. 
Strain Collection Species

Source

number

\begin{tabular}{llll}
\hline Sc1 & ZIM 2558 & S. cerevisiae & throat swab \\
Sc2 & ZIM 2566 & S. cerevisiae & sputum \\
Sc3 & ZIM 2247 & S. cerevisiae & adrenal gland \\
Sc4 & ZIM 2255 & S. cerevisiae & lung of man with immune deficiency syndrome \\
Sc5 & ZIM 2260 & S. cerevisiae & bile tube \\
Sc6 & ZIM 2269 & S. cerevisiae & sorghum beer \\
Cg1 & ZIM 2344 & C. glabrata & urine \\
Cg2 & ZIM 2365 & C. glabrata & sputum \\
Cg3 & ZIM 2369 & C. glabrata & bronchoalveolar lavage \\
Cg4 & ZIM 2382 & C. glabrata & urine taken from a permanent catheter \\
Cg5 & ZIM 2385 & C. glabrata & intestine swab (anus, rectum) \\
Cg6 & ZIM 2389 & C. glabrata & urine \\
\hline
\end{tabular}




\section{Table 2 (on next page)}

Susceptibility of clinical isolates against individual drugs. 


\begin{tabular}{lcccccccc}
\hline Strain & \multicolumn{7}{c}{ MIC range [mg/l] } \\
\cline { 2 - 9 } & FLC & ITC & AMB & MPA & MTX & CsA & Fk506 & AMX \\
\hline Sc1 & $4-8$ & $1-2^{+}$ & $0.125-0.5$ & $>120$ & $>200$ & $>16$ & $>400$ & $>400$ \\
Sc2 & $32-64^{*}$ & $2-4^{*}$ & 0.25 & $>120$ & $>200$ & $>16$ & $>400$ & $>400$ \\
Sc3 & $16-32^{+}$ & $2-4^{*}$ & 0.25 & 120 & $>200$ & $>16$ & $>400$ & $>400$ \\
Sc4 & $1-2$ & $0.5-1$ & 0.5 & 120 & $>200$ & $>16$ & 200 & $>400$ \\
Sc5 & $4-8$ & $1-2^{+}$ & 0.25 & 120 & $>200$ & $>16$ & $>400$ & $>400$ \\
Sc6 & $8-16^{+}$ & 1 & $0.125-0.25$ & $>120$ & $>200$ & $>16$ & 200 & $>400$ \\
Cg1 & $2-4$ & 1 & $0.25-0.5$ & $>120$ & $>200$ & $>16$ & $>400$ & $>400$ \\
Cg2 & $2-4$ & $0.5-1$ & $0.5-1^{+}$ & 120 & $>200$ & $>16$ & $>400$ & $>400$ \\
Cg3 & $4-16^{+}$ & $0.125-1$ & $0.125-0.5$ & $>120$ & $>200$ & $>16$ & $>400$ & $>400$ \\
Cg4 & $2-4$ & $0.25-0.5$ & $0.125-0.5$ & $>120$ & $>200$ & $>16$ & $>400$ & $>400$ \\
Cg5 & $64-128^{*}$ & $4-16^{*}$ & 0.5 & $>120$ & $>200$ & $>16$ & $>400$ & $>400$ \\
Cg6 & $128^{*}$ & $128^{*}$ & $0.125-0.25$ & $>120$ & $>200$ & $>16$ & $>400$ & $>400$ \\
\hline
\end{tabular}




\section{Table 3(on next page)}

Interactions of azole antifungals and MPA against C. glabrata ATCC 2001 interpreted by $\mathrm{FICl}$ and $\mathrm{BI}$ 


\begin{tabular}{llllllll}
\hline \multirow{2}{*}{ Drug } & \multirow{2}{*}{ MIC $[\mathrm{mg} / \mathrm{l}]$} & \multicolumn{2}{c}{ FICI (+ MPA) } & & \multicolumn{3}{c}{ BI (+ MPA) } \\
\cline { 3 - 4 } \cline { 7 - 8 } & & (range) & INT & & $\Sigma$ SYN $(n)$ & $\Sigma$ ANT $(n)$ & INT \\
\hline FLC & 32 & $1.06-2.5$ & IND & & $6.42 \%(1)$ & $-266.9 \%(15)$ & ANT \\
ITC & 0.25 & $1.25-4.25$ & ANT & & $16.59 \%(2)$ & $-477.41 \%(22)$ & ANT \\
KCT & 0.5 & $1.25-4.125$ & ANT & & 0 & $-229.8 \%(12)$ & ANT \\
VRC & 0.25 & $1.063-2.5$ & IND & & $53.1 \%(7)$ & $-284.2 \%(11)$ & ANT \\
POS & 0.25 & $1.5-4.125$ & ANT & & 0 & $-321.1 \%(9)$ & ANT \\
\hline
\end{tabular}

$1 \mathrm{INT}=$ interpretation, IND $=$ indifference, $\mathrm{ANT}=$ antagonism

$2 n=$ number of significant interactions (out of 49, which combine the entire interaction surface of

3 a single experiment) in one representative experiment with three independent biological replicates

4 for each drug combination tested. 


\section{Figure 1}

Interpretation of the effects of drug interactions against each selected strain with $\mathrm{FICl}$ and $\mathrm{BI}$.

Each small square includes the calculated overall $\mathrm{FICl}$ and $\mathrm{BI}$ values of several experiments combined for each drug combination and strain; list of strains in Table 1. Yellow indicates synergy and blue antagonism. Darker colors signify confirmation of the effect by both $\mathrm{FICl}$ and $\mathrm{BI}$, and a lighter color only by one model. The interaction was considered significant, if it was confirmed with at least one model. Interpretation of $\mathrm{FICl}$ : synergistic $\leq 0.5$, indifferent 0.5-4, antagonistic $\geq 4$ (Odds, 2003). $\mathrm{FICl}_{\min }$ was reported unless the value of $\mathrm{FICl}_{\max }$ was

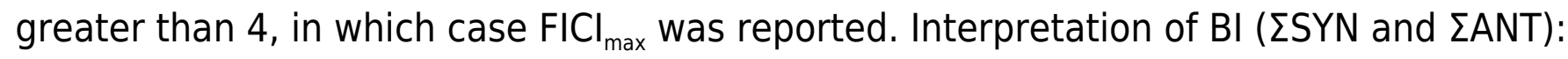
positive values are interpreted as synergy and negative as antagonism, where the absolute sum of all $\Sigma$ SYN or $\Sigma$ ANT was considered to be a weak (0-100\%), moderate (100-200\%), or strong (> 200\%) interaction (Meletiadis et al., 2005) . FICl = fractional inhibitory concentration index, $\mathbf{B I}=$ Bliss independence, $\mathbf{\Sigma S Y N}=$ sum of all significant positive values calculated by the BI model, $\mathbf{\Sigma} \mathbf{A N T}=$ sum of all significant negative values calculated by the Bl model. 


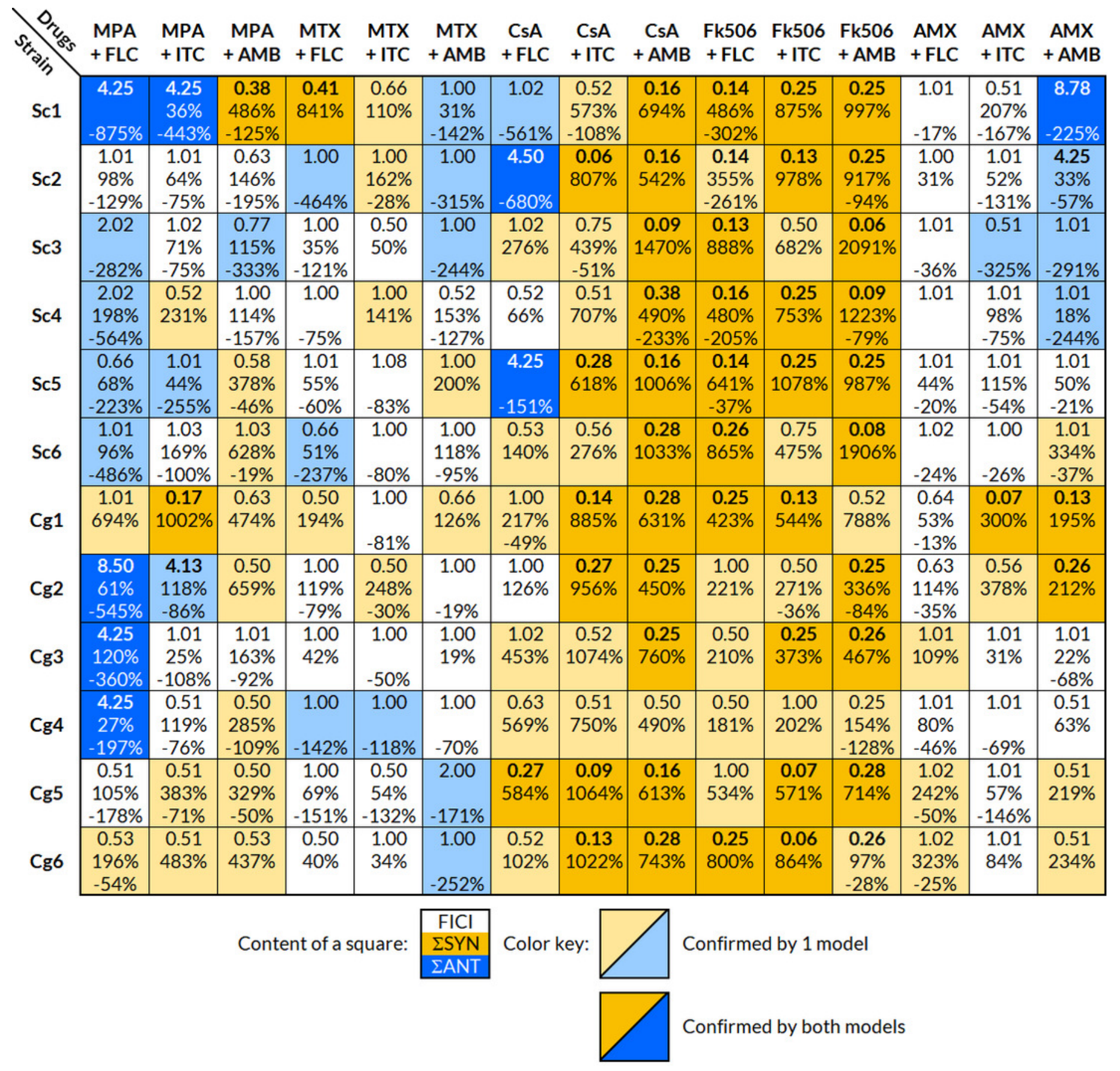




\section{Figure 2}

Role assessment of $P D R 1$ and $C D R 1$ for the antagonism in the drug combination of FLC+MPA against C. glabrata ATCC 2001.

(A) Antagonistic interaction (interpreted by the BI model with $\Sigma$ ANT of $-266.9 \%$ ) observed via relative growth in a checkerboard assay with C. glabrata ATCC 2001 against various combinations of MPA and FLC in YPD at $37^{\circ} \mathrm{C}$. Red indicates lower growth. (B) Relative growth in a checkerboard assay with Cgpdr1 $\triangle$ against various combinations of MPA and FLC in YPD at $37{ }^{\circ} \mathrm{C}$. Antagonism is visible (interpreted by the BI model with $\Sigma A N T$ of $-320.79 \%$ ), most emphasized at MPA $8 \mathrm{mg} / \mathrm{l}$ and FLC $4 \mathrm{mg} / \mathrm{l}$. (C, D) Relative fold change of gene expression for PDR1, CDR1, respectively, in C. glabrata ATCC 2001 after 2 and 4 hours of four different treatments at $37^{\circ} \mathrm{C}$ : YPD broth (untreated) and YPD broth with either $5 \mathrm{mg} / \mathrm{l} \mathrm{FLC,} 5$ $\mathrm{mg} / \mathrm{l} \mathrm{MPA}$, or $5 \mathrm{mg} / \mathrm{l} \mathrm{FLC}+5 \mathrm{mg} / \mathrm{l} \mathrm{MPA}$. The figures show one representative experiment with three independent biological replicates for each strain tested. Statistical analysis was performed in GraphPad Prism using one-way ANOVA and Bonferroni's multiple comparison test. P-value of less than 0.05 was significant, statistically significant differences are marked with *. 
A

ATCC2001, relative growth MPA + FLC [mg/L]

\begin{tabular}{|c|c|c|c|c|c|c|c|}
\hline 128 & $4 \%$ & $4 \%$ & $4 \%$ & $3 \%$ & $4 \%$ & $4 \%$ & $3 \%$ \\
\hline $9 \%$ & $10 \%$ & $10 \%$ & $10 \%$ & $9 \%$ & $8 \%$ & $6 \%$ & $4 \%$ \\
\hline $30 \%$ & $35 \%$ & $36 \%$ & $31 \%$ & $29 \%$ & $26 \%$ & $16 \%$ & $6 \%$ \\
\hline $76 \%$ & $75 \%$ & $73 \%$ & $68 \%$ & $65 \%$ & $60 \%$ & $25 \%$ & $5 \%$ \\
\hline $94 \%$ & $92 \%$ & $93 \%$ & $91 \%$ & $91 \%$ & $77 \%$ & $14 \%$ & $6 \%$ \\
\hline $96 \%$ & $96 \%$ & $95 \%$ & $93 \%$ & $93 \%$ & $63 \%$ & $7 \%$ & $5 \%$ \\
\hline $102 \%$ & $100 \%$ & $100 \%$ & $99 \%$ & $97 \%$ & $36 \%$ & $7 \%$ & $5 \%$ \\
\hline $100 \%$ & $101 \%$ & $100 \%$ & $98 \%$ & $84 \%$ & $23 \%$ & $7 \%$ & $6 \%$ \\
\hline 0 & 2 & 4 & 8 & 16 & 32 & 64 & 128 \\
\hline
\end{tabular}

C

PDR1

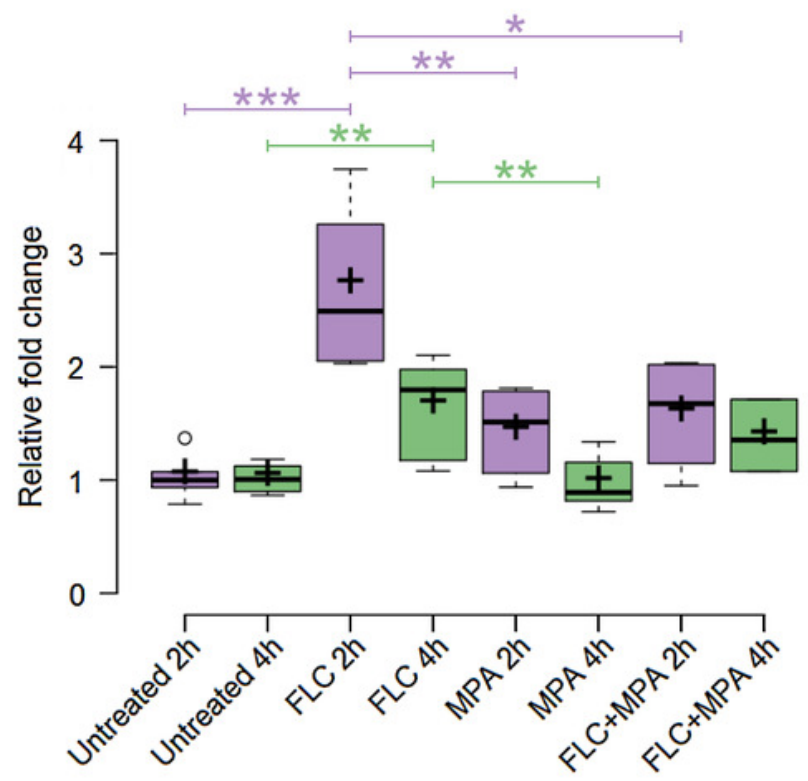

B

Cgpdr1 $\Delta$, relative growth MPA + FLC [mg/L]

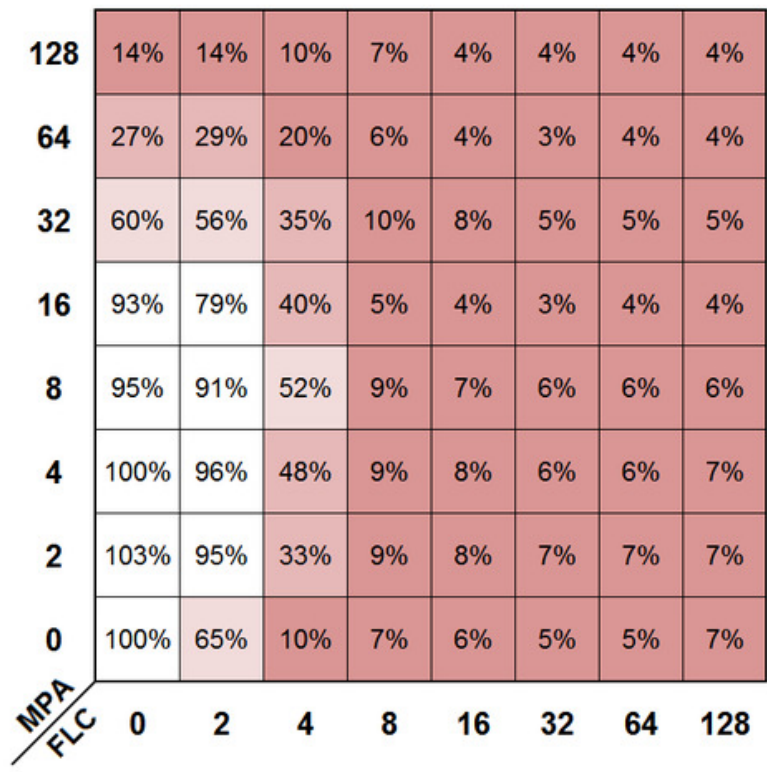

D

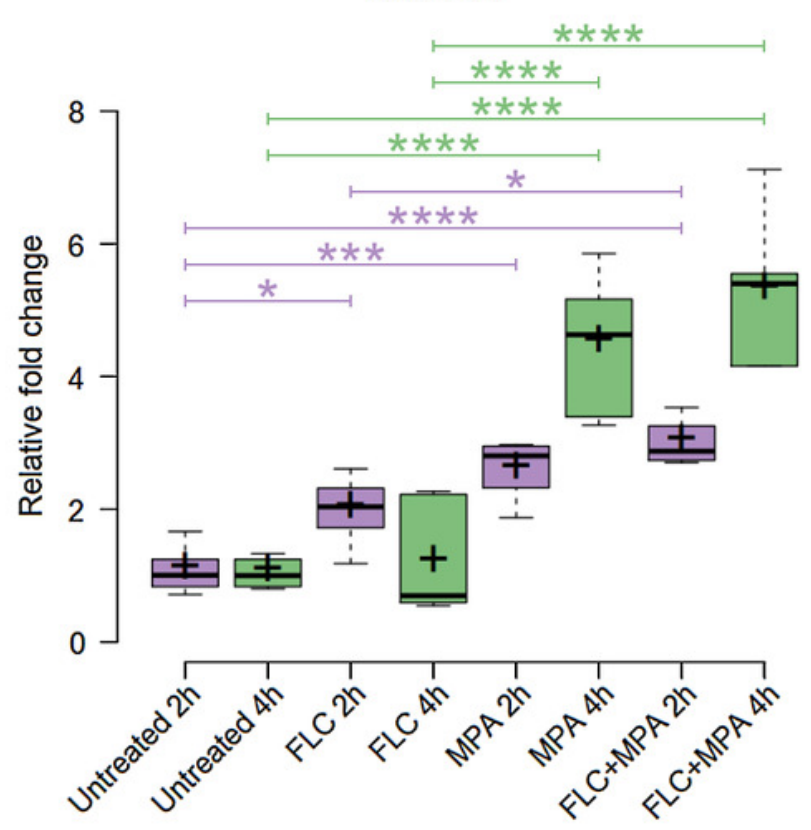

